ensaio

vol $5 \cdot \mathrm{n}^{\circ} 2 \cdot$ out 2003

\title{
UM CURRÍCULO DE CIÊNCIAS VOLTADO PARA A COMPREENSÃO POR TODOS
}

\section{Towards a Science Curriculum for Public Understanding}

Robin Millar*

\begin{abstract}
Explores the reasons why science should be taught to all school students and what the science curriculum should look like. Discusses three aspects of an understanding of science: understanding of science content, understanding of the methods of inquiry used in science, and understanding of science as a social enterprise. (JRH)
\end{abstract}

\section{Resumo}

Aborda as razões para ensinar ciências para todos os estudantes da escola e as características do currículo de ciências. Discute três aspectos de uma compreensão da ciência: compreensão do conteúdo de ciências, compreensão dos métodos de investigação utilizados na ciência, e compreensão da ciência enquanto atividade social.

Uma justificativa freqüente para o ensino de "ciências para todos" é a necessidade de melhorar a educação científica e promover uma melhor compreensão da ciência pelo público em geral. Mas há muitas evidências de que muitos estudantes e adultos tenham pouca compreensão das idéias básicas ou dos processos em ciências. Uma moratória de cinco anos nas mudanças que se seguiram à revisão "Dearing" do currículo nacional ingles cria uma oportunidade para revisão, pelos professores de ensino de ciências, da estrutura e conteúdo do currículo, como instrumento promotor da compreensão de ciências pelo público

\section{CONSIDERAÇÕES SOBRE EDUCAÇÃO CIENTÍFICA}

Na última década, ciências tornou-se, junto à matemática e inglês, assunto central no currículo nacional do Reino Unido. Parece haver amplo consenso, tanto dentro quanto fora do sistema educacional, que todas as crianças devam estudar ciências ao longo do período de escolaridade compulsória, dos 5 aos 16 anos. Dentro ou fora das escolas tem havido pouca oposição a esse aumento da importância de ciências ou à dedicação de $20 \%$

* Universidade de York, Senior Lecturer em Estudos Educacionais, artigo publicado na School Science Review, mar 96, 77 (280). Traduzido por Jordelina Lage Martins Wykrota e Maria Hilda de Paiva Andrade

email:rhm1@york.ac.uk 


\section{ensaio}

vol $5 \cdot \mathrm{n}^{\circ} 2 \cdot$ out 2003

do tempo escolar na educação secundária na faixa de 14 a 16 anos (Key Stage 4), o dobro do tempo dedicado a outros assuntos.

Entre as raras vozes discordantes, Chapman (1991) escreveu sobre a oferta excessiva de educação científica na década de 80 , contestando a validade dos argumentos da educação "para todos" compulsória. De fora da comunidade de educação em ciências, Jenkins (1994) escreveu um artigo forte no The Times argumentando que "o mundo adulto não requer conhecimento profundo de matemática e ciências", e que a importância atribuída a esses assuntos por políticos e industriais é o resultado de um "truque, um acordo confidencial" encenado pela comunidade científica acadêmica. Embora sejam poucas as críticas francas como essas, penso que elas sejam o sinal visível de preocupação e uma insatisfação mais ampla e geral com o ensino de ciências oferecido.

A maior causa dessa insatisfação é o acúmulo de evidência - não apenas no mundo britânico mas por todo o mundo desenvolvido - de que pouco conhecimento científico seja de fato assimilado e compreendido pela maior parte dos estudantes. Os estudos APU (Gamble et al., 1985) mostraram que, aproximadamente, apenas 35\% dos estudantes de 15 anos são capazes de aplicar o conhecimento científico em situações problemáticas simples. Pesquisas no aprendizado dos estudantes em domínios específicos do conhecimento científico apontam na mesma direção: poucos jovens por volta dos dezesseis anos têm uma base sólida sequer dos fatos, princípios, conceitos e idéias mais básicos em ciências. Idéias como a teoria particulada da matéria, o modelo científico do sistema solar, trocas gasosas nas plantas e animais - são todas pobremente compreendidas e há muitas idéias erradas comuns e persistentes (Driver et al., 1994).

Um programa recente de televisão (transmitido pela BBC2 em setembro de 1994) baseado em um trabalho atual nas Universidades de Harvard e Leeds, ilustra isso dramaticamente, mostrando engenheiros graduados incapazes de explicar de onde vem a matéria que constitui um bloco de madeira - e relutantes em aceitar a possibilidade de ter sido do gás carbônico do ar. A mesma pesquisa mostra que a ausência de compreensão básica nos estudantes aparentemente não é percebida pelos seus professores, que constantemente superestimam a compreensão pelos alunos das idéias básicas após ensino - talvez porque os alunos encontram um jeito, apesar disso, de obter resultados razoáveis em testes e exames convencionais. Pesquisas na compreensão de ciências pelo público adulto (Durant et al., 1989) mostram o mesmo quadro: pouca compreensão e, em potencial, muita confusão sobre as idéias científicas básicas.

Argumenta-se que a falta de eficiência do ensino de ciências é uma consequiência do currículo oferecido. Claxton (1991) escreve sobre sua crescente compreensão de que não 


\section{ensaio}

vol $5 \cdot n^{\circ} 2 \cdot$ out 2003

temos problema com a educação em ciências; temos um desastre. Lendo a literatura, conversando com professores e alunos, e assistindo aulas, ... torna-se óbvio que o que está sendo oferecido não dista um pouquinho, mas sim quilômetros do que a maioria dos estudantes quer e precisa aprender.

Será que muitos estudantes aprendem pouco ciências porque simplesmente não podem enxergar relevância no que aprendem? E essa avaliação feita por eles, estaria substancialmente correta, como argumenta Jenkins?

A essas preocupações eu acrescentaria uma terceira, sobre a uniformidade e inflexibilidade das etapas da maioria dos programas de ciências. Cada lição baseia-se na anterior, introduzindo novas idéias. As "grandes idéias" se perdem na massa de detalhes. Para muitos estudantes é simplesmente uma idéia após a outra; antes que você tenha alcançado completamente uma já está mergulhado em outra. Não há variedade de etapas a serem percorridas, há pouco tempo para consolidação das idéias, não há ritmo de aprendizado, apenas, para a maioria dos estudantes, uma avalanche de idéias fora de seu controle.

Na Inglaterra e País de Gales, temos visto uma sucessão de mudanças no currículo de ciências ao longo dos últimos 8 anos, a maioria delas planejada e introduzida de modo apressado. Agora temos a promessa de um período de cinco anos de consolidação. É importante que este intervalo seja usado para reflexão sobre os propósitos e a estrutura do currículo de ciências na preparação para a próxima revisão, quando ela chegar. Nesse artigo, quero explorar duas questões:

- Por que ciências deve ser ensinada para todos os alunos?

- E (à luz das respostas à questão anterior), qual deve ser "a cara" de um currículo de ciências?

\section{POR QUE ENSINAR CIÊNCIAS, E POR QUE "PARA TODOS"?}

No primeiro ASE Science Teacher's Handbook, Milner (1986) aborda a questão “por que ensinar ciências, e por que para todos?" Ele argumenta que ciências ou, sob esse aspecto, qualquer outro assunto só pode requerer um lugar no currículo se pudermos mostrar três coisas sobre ele:

- Que contribui com habilidades, conceitos e perspectivas específicas, distintas, não oferecidas por outras disciplinas.

- Que não é possível de ser adquirido informalmente, mas apenas sob instrução formal. 


\section{ensaio}

vol $5 \cdot \mathrm{n}^{\circ} 2 \cdot$ out 2003

• E que sua aquisição tenha importância e valor.

O primeiro pode ser rapidamente admitido. Ciências é um assunto específico - o comportamento do mundo natural - e usa conceitos e idéias específicos para expressar nossa compreensão. E há características específicas na sua abordagem investigativa, embora não sejam fáceis de especificar-se em detalhes.

O conhecimento científico também atende ao segundo critério. É muito claro que muitas das principais idéias científicas são contrárias às do senso comum, como argumentou recentemente Wolpert (1992); elas não são adquiridas simplesmentre com a experiência de vida. A experiência dos professores com os problemas da aprendizagem por redescoberta e a persistência das concepções errôneas ou alternativas mesmo com evidências conflitantes são argumentos convincentes de que as coisas sejam assim. O segundo critério, entretanto, pode ser mais significante no que diz respeito aos chamados processos da ciência: argumentei, em outro lugar (Millar, 1989; Millar \& Driver, 1987) que "habilidades processuais" tais como observar, classificar, predizer e outras são adquiridas informalmente - sem dúvida são usadas por crianças bastante novas - e que o objetivo do ensino de ciências não é desenvolvê-las, mas encorajar os estudantes a usar capacidades que eles já possuem na exploração de questões científicas.

A terceira condição, que ciências seja de importância e valor, coloca a questão "importante e de valor para quem" e "para quê?". Milner apresenta os modos nos quais ciências é

Justificativa intrínseca

O conhecimento científico é um produto cultural de grande poder intelectual e beleza. Seres humanos têm uma curiosidade sobre o mundo natural que o conhecimento científico pode satisfazer. Muitas pessoas consideram possuí-lo recompensante e realizador do ponto de vista pessoal.

Justificativa instrumental

O conhecimento científico é necessário para:

- tomar decisões práticas sobre quetões do cotidiano de modo informado.

- participar da tomada de decisões em questões que tenham um componente científico/tecnológico.

- trabalhar em empregos que envolvam ciência e tecnologia (em vários níveis).

Thomas e Durant (1987) abordam a mesma questão sob uma perspectiva diferente, em um artigo intitulado: "Por que devemos promover a compreensão de ciências pelo público?" Eles expõem os diferentes argumentos que podem ser encontrados na literatura sobre compreensão pelo público. Esses podem ser agrupados em cinco categorias distin- 
tas.

2.1. O argumento econômico: que exista uma conexão entre o nível de compreensão de ciências pelo público e o nível de saúde econômica da nação. Além disso, o sucesso científico e tecnológico de uma nação é visto como um sinal de reputação internacional. Mantê-lo depende de constante suprimento de pessoal técnica e cientificamente qualificado.

2.2. O argumento da utilidade: de que a compreensão de ciências e tecnologia seja útil do ponto de vista prático, especialmente para quem vive numa sociedade científica e tecnologicamente sofisticada. Essas pessoas estariam melhor munidas para tomar decisões sobre dieta, segurança e outras coisas, avaliar a propaganda dos fabricantes e fazer escolhas mais sensatas enquanto consumidores.

2.3. O argumento democrático: de que para qualquer indivíduo tomar parte de uma discussão debate ou decisão sobre temas com algum componente científico é necessária uma compreensão de ciências. Decisões sobre transporte, política energética, teste de drogas e tratamentos, destino de resíduos e outras têm de ser tomadas. Deve haver alguma responsabilidade pública no direcionamento de algumas pesquisas científicas e envolvimento público nas decisões sobre aplicar-se ou não esse conhecimento.

2.4. O argumento social: que é importante manter ligações entre ciências e cultura geral. A especialização e o crescimento da natureza técnica da ciência moderna são vistos como problemas sociais que levam a uma fragmentação incipiente - e à alienação da maior parte do público a respeito da ciência e tecnologia. Um argumento relacionado é tomado do lado da ciência: que a melhoria da compreensão pública da ciência vai levar a uma maior simpatia por ela e conseqüentemente, ao financiamento para ciência e tecnologia.

2.5. O argumento cultural: de que a ciência seja uma importante - certamente $a$ principal - aquisição de nossa cultura e que o público jovem precisa ser capacitado a entendê-la e apreciá-la. Devemos festejar a ciência como um produto cultural.

Esses cinco argumentos correspondem muito de perto às justificativas oferecidas por Milner. Até agora, apenas os apresentei. Na próxima seção quero examiná-los mais criticamente e usá-los para desenvolver critérios para decisões sobre o currículo de ciências.

\section{CONSIDERANDO OS ARGUMENTOS PARA O ENSINO DE CIÊNCIAS}

Antes de considerar cada um dos cinco argumentos listados anteriormente, é importante reconhecer que o currículo escolar de ciências tem de desempenhar duas tarefas: para uma 


\section{ensaio}

vol $5 \cdot \mathrm{n}^{\circ} 2 \cdot$ out 2003

minoria dos jovens, o ensino de ciências dos 5 aos 16 anos é o primeiro estágio na sua formação como cientistas. Eles entrarão em cursos e talvez sigam carreiras que envolvem ciências. Para eles, o programa precisa fornecer uma base satisfatória para os estudos posteriores. A maioria dos jovens, entretanto, não vai estudar ciências depois. Para eles estudar ciências é parte de sua educação geral, de sua preparação para a vida em uma democracia técnica, industrializada, moderna.

\begin{tabular}{|c|c|c|}
\hline O currículo de ciências funciona c & hmo: & \\
\hline $\begin{array}{l}\text { primeiros estágios de uma } \\
\text { formação em ciências }\end{array}$ & & acesso à cultura científica básica \\
\hline para uma minoria & & para uma maioria \\
\hline
\end{tabular}

No momento, no Reino Unido, como na maior parte de outros países, o mesmo currículo tem de atender as duas demandas. Mas é bastante claro que nenhum currículo possa desempenhar essas duas finalidades satisfatoriamente. Entretanto é suficientemente claro que o presente currículo evoluiu inteiramente de uma linha de descendência do currículo desenhado para formação científica. O Currículo Nacional de ciências é filho(a) do GCSE e neto(a) do GCE nível O. Mudou nos limites, alguns tópicos foram um pouco ajustados, ele é menos formal e matemático - mas sua ancestralidade é clara. Com efeito assumimos, durante o período de adequação à compreensão e finalização da bifurcação GCE/CSE, que o caminho para um currículo de ciências para todos era essencialmente modificar o ensino no currículo de ciências para torná-lo mais acessível.

O resultado foi tornar o currículo de ciências para 5 a 16 anos menos adequado para preparação para estudos avançados enquanto, ao mesmo tempo, falhamos amplamente em torná-lo motivador ou acessível para a maioria. A evidência disso foi a redução na proporção dos estudantes que escolhiam estudar ciências, particularmente Física, na educação posterior à obrigatória, e a crescente e (e amplamente justificada) percepção de que estudar ciências, depois dos 16 anos, é uma opção difícil de ser realizada pelos jovens, envolvendo um considerável acréscimo em dificuldades a partir dos cursos anteriores; e, para os últimos, os baixos níveis de compreensão discutidos anteriormente. O currículo presente cai entre dois paramares e é inadequado para seus ambos propósitos.

Ao invés de considerar a possibilidade de modificações graduais posteriores, penso que necessitamos perguntar: qual deve ser o perfil do currículo de ciências se desenhado com as necessidades da maioria em vista? Qual deve ser "a cara"de um currículo de ciências desenhado para promover a cultura científica da maioria das pessoas? Essas são as 


\section{ensaio}

vol $5 \cdot n^{\circ} 2 \cdot$ out 2003

questões que gostaria de focar ao considerar os cinco argumentos para se ensinar ciências. Posteriormente, como uma questão separada, poderíamos desejar perguntar: seria tal currículo uma preparação razoável também para para estudos posteriores de ciências pela minoria que escolhesse isso?

\section{$O$ argumento econômico}

$\mathrm{O}$ argumento econômico indica a conexão entre tecnologia e criação de riqueza industrial, e a necessidade de um contínuo fornecimento de especialistas em ciências para manter e desenvolver a infraestrutura tecnológica. Esse é um argumento forte para fazer um currículo de ensino de ciências disponível para alguns estudantes, mas como relativamente poucos cientistas altamente instruídos sejam necessários, não sustenta, como Chapman (1991) argumenta em detalhe, a necessidade de ensinar ciências para todos os estudantes até o final do ensino obrigatório. A causa da promoção do ensino ciências para todos tem de ser defendida, e certamente isso é comumente feito, em termos dos outros quatro argumentos: o da utilidade, o democrático, o social e o cultural.

\section{$O$ argumento da utilidade}

$\mathrm{O}$ argumento da utilidade indica que o conhecimento científico é necessário para lidar-se com aspectos da vida cotidiana. Mas, a maioria das peças de equipamento técnico pode ser usada com pouca compreensão de como elas funcionam e o avanço técnico tende a fazer tal compreensão gradualmente menos (ao invés de mais) necessária. Poucas decisões práticas são tomadas com base em conhecimento científico. Quando ele é usado em colocações do dia a dia, em geral é encapsulado na forma de uma regra simples do senso comum, sem precisão científica, como: “metais conduzem"ou "se um aparelho elétrico pára de funcionar, provavelmente é uma conexão quebrada". Layton (1993) mostra que o conhecimento científico invariavelmente tem que ser trabalhado e recontruído para tornar-se disponível na orientação de uma ação prática.

Tanto quanto eu saiba, não há evidências de que físicos sofram menos acidentes em estradas porque compreendam as leis newtonianas do movimento ou que isolem termicamente melhor suas casas, em comparação com outros grupos sociais, porque entendam as leis da termodinâmica. Um estudo de pensionistas em Leeds (Layton et al., 1993) mostrou, não surpreendentemente, que suas decisões sobre aquecimento de suas casas eram baseadas em múltiplos fatores, a maioria deles sociais, e não somente na sua compreensão da perda de calor e do isolamento térmico, que era freqüentemente superada por considerações de aspecto estético ou prático. Esses exemplos não sustentam, é claro, que nenhu- 


\section{ensaio}

vol $5 \cdot \mathrm{n}^{\circ} 2 \cdot$ out 2003

ma parte do conhecimento científico seja sempre útil do ponto de vista prático. Mas eles sugerem que o argumento da utilidade da compreensão da ciência é supervalorizado.

Talvez o argumento da utilidade posa ser construído com base numa interpretação mais atenuada de "aplicabilidade". Pode argumentar-se que alguma compreensão de como os artefatos, e mesmo fenômenos naturais, funcionam faz a pessoa sentir-se mais conhecedora e portanto mais confortável, na vida de todo dia. Por certo explicações desse tipo aparecem proeminentemente em publicações científicas populares e aparentam ser amplamente percebidas como pertencentes à cultura científica. Entretanto, é difícil argumentar que um interese nesses assuntos é de maior valor tanto individual quanto socialmente, dentre tantos outros interesses que as pessoas possam ter. Tal interpretação da utilidade mal poderia justificar ensino compulsório de ciências para todos.

Penso que o valor do argumento da utilidade é que ele nos desafia a tomar o critério "aplicabilidade" do conhecimento a sério. Aponta para um currículo de ciências com uma ênfase mais forte em um modo de conhecer mais tecnológico sobre os fenômenos, em conhecimento mais aplicável imediatamente do que em princípios abstratos mais gerais.

\section{O argumento democrático}

O argumento democrático é que seja necessária uma compreensão de ciências para participar em discussão, debate ou decisão sobre temas relacionados à ciência em sociedade. Aqui também há problemas se levamos essa pretensão mais a fundo. Primeiro precisamos perguntar: que nível de compreensão é necessário se não quisermos trivializar as questões? Mesmo cientistas em exercício da profissão reconhecem que frequentemente não estão suficientemente informados sobre um assunto no qual não são especialistas de modo a serem capazes de formular uma opinião firme. Segundo, existe o número de questões dissociadas. Podemos realmente preparar o público jovem para sustentar uma opinião informada em engenharia genética, pesquisa em embriões, poderio nuclear, destino de resíduos tóxicos, os riscos para a saúde de uma dieta de gorduras saturadas ou não, os perigos possíveis de viver-se próximo à linhas de alta tensão, e assim por diante? Mesmo que possamos, podemos antecipar as novas questões que se colocarão ao longo da vida deles? Como a resposta é certamente um não, estamos então pretendendo que exista algo transferível que os estudantes possam aprender, estudando alguns desses problemas, que irá prepará-los melhor para lidar com outros no futuro? Se assim for, então devemos tentar evidenciar que núcleo transferível seja esse.

O argumento democrático indica, eu penso, não propósitos vagos e mal definidos sobre 


\section{ensaio}

vol $5 \cdot n^{\circ} 2 \cdot$ out 2003

"habilidades de tomar decisões" ou "aumento do conhecimento de ciências na sociedade", mas antes a necessidade de dar prioridade curricular a conhecimentos fundamentais a partir dos quais o conhecimento mais detalhado necessário para fundamentar questões particulares pode ser construído, se e quando for necessário. Retornaremos depois à questão do que esses "conhecimentos fundamentais" possam ser.

\section{Os argumentos cultural e social}

$\mathrm{O}$ argumento cultural é de que a ciência seja a principal aquisição de nossa cultura e, portanto, que todos os jovens devam ser ajudados a compreendê-la e apreciá-la. A justificativa curricular para o ensino de ciências então torna-se semelhante à da literatura, arte ou música. Pode-se arrazoar que o argumento cultural para ciências seja mais forte do que para esses outros campos do conhecimento; ciências não é só a principal aquisição cultural - é $o$ produto definidor de nossa cultura, aquilo que podemos esperar mais confiantemente que será identificado pelos historiadores e arqueólogos do futuro como característico de nossos tempos. E, como argumenta Midgley (1992):

Qualquer sistema de pensamento que desempenhe a enorme parte que a ciência desempenha no momento em nossas vidas também molda nossos mitos orientadores e colore nossa imaginação profundamente. Não é apenas uma ferramenta.

Certamente essa seria uma cultura estranha de fato se não quisesse passar para novas gerações seu sistema de pensamento mais proeminente. O problema para os professores de ensino de ciências é que nós não pensamos realmente, e eu gostaria de sugerir isso, o que significaria ensinar, as leis de Newton da gravitação universal, ou a descoberta de Lavoisier do oxigênio, ou a descoberta dos micróbios pelos primeiros microscopistas como marcas culturais, ao invés de como conhecimentos úteis ou como ilustração de métodos de investigação científica.

O argumento social é fortemente relacionado ao cultural. É que é importante para a coesão social manter os elos entre a ciência e a cultura geral. A ciência no século 20 tornou-se cada vez mais remota e técnica e difícil para um leigo compreender. $\mathrm{O}$ abismo entre ciência e o resto da cultura ameaça a saúde de ambos. A despeito do fato de que possamos concordar que esta seja uma preocupação, ela não conduz obviamente a nenhum critério específico para o desenho curricular. Podemos estar negligenciando um recurso educacional poderoso na construção de um modelo de currículo de ciências que dê pouca ou nenhuma importância aos escritos de autores como Stephan Jay Gould, Paul Davies, Richard 


\section{ensaio}

vol $5 \cdot \mathrm{n}^{\circ} 2 \cdot$ out 2003

Dawkins ou Primo Levi.

\section{UM CURRÍCULO DE CIÊNCIAS VOLTADO PARA COMPREENSÃO POR TODOS}

Para resumir a seção precedente, eu coloquei que o argumento da utilidade aponta para uma ênfase mais tecnológica no currículo de ciências, que o argumento democrático implica na necessidade de focar na compreeensão das idéias fundamentais que proporcionam uma base para o aprendizado de detalhes específicos quando esses forem necessários, e que a importância cultural da ciência proporciona um argumento forte para a introdução de todos os estudantes em alguns dos maiores avanços na nossa compreensão do mundo, vistos como acontecimentos e aquisições culturais significantes para serem celebrados.

Agora eu gostaria de considerar a forma de currículo de ciências a que essas idéias poderiam conduzir, vendo de cada vez cada um dos tres aspectos de uma compreensão de ciências:

- compreensão do conteúdo científico (ou conhecimento científico substantivo);

- compreensão dos métodos de investigação usados em ciência;

• compreensão da ciência como um empreendimento social.

\section{Compreendendo o conteúdo de ciências}

Por que o conhecimento substantivo da ciência deve ser incluído em um currículo de ciências acessível para compreensão de todos? Embora esteja em voga desdenhar um "modelo deficitário", simples, acessível para compreensão de ciências pela maioria dos estudantes, - a idéia de que o "problema" é que as pessoas simplesmente não têm conhecimento científico substantivo suficiente - caso é que, certamente, ninguém poderia ser considerado alfabetizado cientificamente sem alguma compreensão de algum conteúdo de ciências. Mas qual conteúdo?

Dada a evidência da ausência de compreensão dos estudantes em tantas áreas básicas, o princípio orientador a respeito do currículo certamente deve ser: faça menos mas faça-o melhor. É quase um lugar comum observar que o currículo é sobrecarregado. Como resultado, não é claro sobre suas prioridades; os estudantes (e talvez também os professores) são incapazes de ver madeira relacionada às arvores. O inchaço dos livros didáticos, pacotes curriculares e programas de estudos dão a impressão de falta de consenso sobre as prioridades e sobre estrutura. O que é central? O que realmente importa? 


\section{ensaio}

vol $5 \cdot n^{\circ} 2 \cdot$ out 2003

Gostaria de sugerir que o currículo de ciências para a faixa de 5 a 16 anos deva ter dois objetivos a respeito do conteúdo científico:

- ajudar os estudantes a tornarem-se mais capacitados nas suas interações com o mundo material pela ênfase em um modo de conhecer mais tecnológico, mais útil do ponto de vista prático;

- desenvolver gradualmente a compreensão dos estudantes de um pequeno número de "modelos mentais" (ou "estórias") sobre o comportamento do mundo natural.

Não há espaço nesse artigo para desenvolver extensamente essas idéias, mas tentarei usar alguns exemplos para ilustrar o que tenho em mente.

\section{Uma ênfase mais tecnológica}

Tomemos energia como exemplo - um conceito tido como uma das grandes aquisições em ciências. O problema é que o conceito científico de energia é simplesmente muito abstrato e difícil para a maioria dos jovens até 16 anos. Poderíamos fazer melhor se baseássemos o tratamento dado a esse conceito pelo currículo no conceito cotidiano de energia, que é essencialmente sinônimo do de combustível - algo que é utilizado em processos, que faz as coisas acontecerem, que é de valor, um recurso limitado, e que, portanto, deve ser usado com parcimônia. O currículo focaria idéias úteis como uso de combustível e eficiência de combustível. Idéias sobre isolamento podem ser trabalhadas com base em um simples modelo "calórico" de energia, que é útil (e é largamente usado pelos engenheiros) nesse contexto.

Similarmente, muitos estudantes podem lidar admiravelmente com um modo de conhecer tecnológico sobre circuitos elétricos simples, usando idéias sobre circuitos fechados para ligar e desligar coisas quando necessário e resistores variáveis para controlar brilho de lâmpadas ou velocidade de motores. Mas eles rapidamente tornam-se perdidos nos modelos teóricos de corrente, voltagem e resistência. Mesmo eletricistas profissionais ou consertadores de equipamentos raramente usam modelos formais, mas baseiam sua compreensão em modelos mais pragmáticos e regras mais práticas. Em mecânica, uma abordagem tecnológica poderia incluir o uso de alavancas, engrenagens, roldanas e poderia explorar friç̧ão e resistência do ar em relação a problemas práticos, sem introduzir a dificuldade da idéia contra-intuitiva de inércia.

Essas idéias estão longe de serem exaustivas. Destinam-se apenas a ilustrar tópicos onde uma abordagem significativamente diferente pode ser adotada. Há outros tópicos e talvez também alguns tópicos novos, tais como informação, onde um modo tecnológico de 


\section{ensaio}

vol $5 \cdot \mathrm{n}^{\circ} 2 \cdot$ out 2003

conhecer pode ser um objetivo mais apropriado para o currículo do que uma compreensão teórica abstrata.

Esse também pode ser o ponto de conhecer que há um lugar, talvez mesmo uma necessidade, no currículo de ciências, para uma pequena quantidade do que pode ser chamado "conhecimento científico geral". Por exemplo, pode ser importante para os alunos saber que metais vêm de minérios que são extraídos da crosta terrestre, e que plástico são feitos (na maior parte) de óleo - sem necessariamente saber muito sobre os processos ou reações químicas envolvidas.

\section{Modelos poderosos}

Modelos são importantes porque estão, como um esforço intelectual, no coração da ciência. O objetivo central da ciência é propor explicações para os fenômenos naturais; a forma tomada por essas explicações é a de uma estória ou modelo mental que dá um significado ao pensamento sobre o que acontece, considerando as coisas que observamos e imaginando como as coisas mudariam em novas situações.

Modelos desse tipo entretanto raramente são aplicados em situações do cotidiano. Sua inclusão no currículo não pode ser justificada por um simples apelo ao argumento da utilidade, embora eles possam, é certo, prover explicações para ações que levamos a cabo com base na fé, por exemplo, quando seguimos recomendações médicas sobre o curso de um tratamento ou sobre como mudanças em nossa dieta. Alguns modelos também proporcionam a compreensão básica que é essencial para alcançar os ganchos para temas chave envolvendo aplicações da ciência. Por si só eles não proporcionam tudo que necessitamos saber para ter uma opinião informada sobre o tema; mas sem o conhecimento básico que eles proporcionam é difícil ver como algum conhecimento racional seja possível. Assim, por exemplo, Andersson (1990) mostra como uma compreensão dos possíveis efeitos da poluição pela descarga dos motores de veículos depende da compreensão do modelo científico de reação química.

Entretanto, ele argumenta:

Os conceitos aqui usados - átomo, molécula, reação química - devem ser parte do instrumental mental de qualquer aluno(a) ao deixar a escola. Eles são conceitos chave que ajudam a construir um modelo grosseiro de várias situações, por exemplo, o próprio ambiente de trabalho. Esses conceitos nos capacitam a formar um quadro geral e proporcionam uma base para investigações posteriores.(pp53-4) 
Alguns modelos, por outro lado, como o modelo científico do sistema solar, têm muito pouca utilidade prática e nem substanciam a compreensão de questões. Mas, a idéia de que a Terra gira ao redor do Sol ( e não ao contrário) e gira ao redor de seu próprio eixo, e o modo como isso influencia as estações e o dia/noite, é certamente algo que uma pessoa precisa ser ajudada a conhecer como parte de sua educação geral. É parte da introdução ao conhecimento sobre quem somos e o tipo de universo que habitamos. Assim também, embora de um modo diferente, é o conhecimento da genética e hereditariedade e da evolução. O objetivo desses modelos serem incluídos no currículo é amplamente cultural - essas idéias são produtos culturais de beleza e significância e seu conhecimento e compreensão é enriquecedor da vida.

Os critérios, então, para escolher quais modelos incluir no currículo escolar de ciências são seu significado cultural e seu papel na sustentação de uma compreensão, em termos amplos, de questões que podem ser de domínio público ou de iniciativas pessoais. Os modelos que gostaria de listar, sem ordem de prioridade, são:

- o modelo atômico/molecular da matéria ( com ênfase na compreensão de reações químicas como rearranjos da matéria).

- modelos dos sistemas Terra-Lua, Terra-Sol, do Sistema Solar, e do universo.

- o modelo fonte-radiação-receptor das interações à distância (levando a um modelo de raios da luz e visão).

- o modelo de campo de interações à distância (gravitação, magnetismo, campos elétricos).

- a teoria microbiana das doenças infecciosas.

- o modelo de herança gênica.

- a teoria de Darwin da evolução.

- modelos de evolução da crosta terrestre (formação de rochas, placas tectônicas).

Desses, os dois primeiros devem ser usados, em parte, para desenvolver idéias sobre tamanho, escala e distância, das enormes às mínimas. A teoria microbiana também é valiosa para isso, introduzindo entidades numa escala entre o visível e o atômico/molecular. Os dois últimos da lista devem ser usados, em parte, para desenvolver idéias sobre escala de tempo.

Algumas outras elaborações e aplicações são também importantes. Por exemplo, é importante explicitar a idéia de reações químicas em processos biológicos de modo que o estudante possa perceber que a digestão proporciona materiais para a construção de novos tecidos, ou que plantas aumentem seu volume por meio de reações químicas 


\section{ensaio}

vol $5 \cdot \mathrm{n}^{\circ} 2 \cdot$ out 2003

usando materiais naturais do seu ambiente. $O$ ciclo de alguns materiais chave (por exemplo, o oxigênio e o gás carbônico da atmosfera), é também uma idéia importante, que depende de um certo nível de compreensão dos processos moleculares/atômicos dentro de (eco)sistemas fechados.

Se nós realmente quizermos "fazer menos, mas fazê-lo melhor", então, algum conteúdo bem estabelecido deverá haver, inevitavelmente. Algumas omissões notáveis na listagem anterior são os modelos de Newton do movimento, o modelo científico de energia e troca (entropia), um monte de detalhes químicos, ondas, a compreensão científica dos circuitos elétricos, embora muito disso possa permanecer dentro de uma ênfase mais tecnológica como discutido acima.

\section{Compreendendo os métodos da ciência}

Um segundo aspecto da compreensão de ciências envolve conhecimento sobre os métodos da investigação científica. A maior dificuldade, entretanto, é que não há concordância universal sobre o que sejam esses métodos. Muitas das idéias que foram (e ainda são) comunicadas, tanto implícita quanto explicitamente, pelo currículo de ciências sobre os métodos da ciência são ingênuas e contra-produtivas para a compreensão pelo público do ponto de vista científico. É o caso dos "Processos da ciência", e a versão de 1991 do Currículo Nacional (Sc1)(DES/Welsh Office, 1991). A idéia de que a metodologia científica é para começar com observações imparciais para, em tese, procurar padrões, e então formular hipóteses a partir das quais previsões específicas possam ser feitas e testadas experimentalmente, é uma caricatura de como os cientistas trabalham; e, na mão dos alunos, não leva a conhecimento científico ou compreensão da ciência. As crianças chegam ao estudo formal de ciências, aos 5 anos, já capazes de observar, classificar, supor, prever, comparar "com imparcialidade", e assim por diante, com altos níveis de habilidades em contextos onde visualizem um propósito para empenharem-se. Não há necessidade de gastar tempo de aulas desenvolvendo essas "habilidades".

Claro que é mais fácil criticar o ensino do método científico do que fazer propostas claras e realísticas para melhorá-lo. Penso que uma questão crítica para ser resolvida, em princípio, é se consideraremos uma compreensão do método científico valiosa porque ela proporciona um método de investigação útil do ponto de vista geral, que as pessoas deveriam ser encorajadas a usar mais amplamente (o argumento de transferência de habilidades) ou porque seja importante para qualquer um conhecer algo sobre como o conhecimento científico foi e é obtido. A primeira justificativa é baseada no argumento da utilidade e a segunda, nos argumentos democrático, social e cultural. Há poucas evidênci- 


\section{ensaio}

vol $5 \cdot n^{\circ} 2 \cdot$ out 2003

as para sustentar a primeira; não só não é possível alguém descrever o método científico em detalhe como está longe de ser claro que a abordagem científica seja útil ou apropriada na maioria das situações cotidianas de tomada de decisão. Por outro lado, não há algoritmo universal para descobrir ou para “pesar os prós e contras”. Por outro lado, conhecer (em oposição a simplesmente consentir com) a explicação científica de um fenômeno envolve ser capaz de dar razões para idéias retidas ou proposições relativas às mesmas serem verdadeiras. Então, uma compreensão do conteúdo de ciências necessariamente envolve algum conhecimento sobre como essas idéias chegaram a ser obtidas, e sobre as garantias para aceitá-las como válidas e úteis.

Então, se nosso objetivo, no currículo de ciências, é desenvolver a compreensão dos estudantes dos caminhos nos quais o conhecimento científico é obtido, é util separar duas linhas distintas:

- Uma tem a ver com a coleta de dados que podem servir de evidências para fundamentar um caso. Isso envolve a compreensão de alguns conceitos procedurais, tais como precisão, fidedignidade e validade. Tem a ver com a relação entre uma medida ou observação e a "verdade". Também inclui uma noção adequada do que seja mensuração em si ( a idéia de uma unidade padrão como método de contagem ) do procedimento no uso de um modelo em termos das relações entre variáveis e de raciocínio lógico em situações envolvendo muitas variáveis. Muitas dessas idéias se aplicam de modo geral na investigação sistemática, não apenas em ciências e centram-se ao redor da noção de evidência e da qualidade (poder de persuasão) de uma evidência. As implicações curriculares, talvez, sejam que o trabalho prático precisa dar mais ênfase à incerteza e ao erro. Estimativas de precisão e fidedignidade ( a necessidade de repetir medidas) e validade (você está medindo o que pensa que está medindo?) precisam tornar-se muito mais lugar comum, desde uma idade mais precoce. Devemos tentar evitar qualquer qualquer sugestão de que exista um método infalível ou algoritmo para obter-se o tipo de conhecimento que possa convencer outras pessoas. Essa necessidade não envolve tarefas com um alto nível de demanda conceitual: convencer os outros de que o isolante A realmente é melhor do que o B, ou que as solas do sapato $\mathrm{X}$ realmente aderem melhor do que as do sapato Y, em princípio, a suprem. E o uso de evidência para persuasão pode necessitar de uma audiência, real ou especificamente criada na sala de aula, se é para atingir-se o objetivo desejado.

- Uma segunda linha separada tem que lidar com a teoria em ciência. Envolve a compreensão de que o propósito da ciência é gerar explicações do mundo físico que 


\section{ensaio}

vol $5 \cdot \mathrm{n}^{\circ} 2 \cdot$ out 2003

dêem conta dos fenômenos observados e possam predizer outros, ou sugerir fenômenos para serem procurados ou criados. o que as teorias que propomos fazem não é simplesmente reafirmar os dados em termos diferentes. Elas são conjecturas, feitas com base em dados e evidências disponíveis, mas nunca resultam completamente dos dados. Teorias não emergem das evidências; sempre há um elemento de especulação criativa. Elas não informam sobre os dados mas propõem explicações sobre eles. Teorizar envolve imaginação e conjecturas e riscos de errar. Compreender esse aspecto do método científico envolve o reconhecimento da teoria separada dos dados, e a capacidade de relacionar teoria e dados adequadamente - dizer, por exemplo, quando determinados dados estão ou não em acordo com uma teoria dada (ou muitas) e formular conclusões lógicas a partir disso.

\section{Compreendendo ciências como um empreendimento social}

Dos três aspectos de uma compreensão de ciências a serem considerados para listar especificações curriculares, talvez esse seja o mais difícil. Muitos professores de ciências (por exemplo, aqueles associados com o movimento CTS, Solomon, 1993), concordam que essa seja uma dimensão importante, mas frequentemente não é claro o que é "sobre ciências", que eles querem que os alunos saibam. De um ponto de vista curricular, uma questão chave é clarificar exatamente o que significa essa terceira dimensão. O que, precisamente, queremos que os jovens compreendam sobre as relações entre ciências e estrutura social?

Gostaria de apontar duas idéias ( embora sabendo que podem existir outras ):

- Que o trabalho científico é um produto sustentado socialmente. Que é desenvolvido por meio de um esforço para compreender, dar sentido e comunicar idéias compartilhadas. Idéias emergem da ação sobre o mundo, não apenas de falar sobre ele.

- Que existem diferenças cruciais entre a ciência no laboratório e o mundo real. No laboratório, as situações são simplificadas, de modo que uma entidade pode ser isolada da interferência dos outros e então compreendida. Situações reais, entretanto, são invariavelmente desorganizadas e complexas. Assim, sempre há uma incerteza sobre como ( e mesmo quando) os achados de laboratório se aplicam; e sobre o peso a ser dado a diferentes partes de evidências. E, na maioria dos casos de disputa, outras formas de conhecimento que não científico, e inclusive valores, são relevantes no processo de tomar decisões. 
Um currículo de ciências para compreensão pública deve pretender ajudar os estudantes a desenvolver sua consciência de ambos. A respeito do primeiro, o currículo poderia promover oportunidades para o aluno conhecer mais sobre o trabalho científico real, pela análise em detalhes de alguns exemplos. Esses devem variar da rotina científica de um trabalho num laboratório histológico hospitalar ou de um analista de água administrativo, à ciência "normal" de muitos pesquisadores empresariais ou universitários, aos trabalhos que quebram padrões nos desenvolvimentos revolucionários em ciências. Isso pode ser feito por leituras ou vídeo, mas também por visitas aos locais onde a ciência é feita. E os estudantes também devem, penso eu, aprender alguma coisa dos processos pelos quais novo conhecimento científico é produzido: a partilha de idéias em congressos e em artigos de revistas, os processos de arbitragem e revisões investigativas, a reprodução e verificação de resultados inesperados.

Se estamos pensando no currículo de 5 a 16 anos, então precisamos de um modelo de progressão nessa área para guiar a escolha de exemplos a ser usada. os estudantes devem, ao londo desse tempo, estudar um número específico de exemplos de trabalhos científicos em alguma profundidade, escolhidos para ilustrar, progressivamente, caminhos científicos de trabalho tais como:

- coleta de dados sistemática e cuidadosa na (por exemplo), monitorização ambiental ou previsão do tempo;

- padrões "indutivos" de investigação (como, por exemplo, em algum trabalho epidemiológico ou de saúde pública);

- verificação, por testes, de uma idéia ( ou de uma predição baseada nela);

- proposta de uma nova visão em uma área (por exemplo, a descoberta de Lavoisier do oxigênio, ou o trabalho de Pasteur com doenças, ou a hipótese da deriva continental e das placas tectônicas.

Uma das mensagens-chave desse tipo de trabalho deve ser a de que não há um único modo da ciência trabalhar para obter novo conhecimento, e não há garantias de se obter sucesso na solução de um problema. Olhando o currículo de 5 a 16 anos como um todo, o objetivo deve ser desenvolver gradualmente as idéias sobre a necessidade de uma base fidedigna de dados, o papel da imaginação na geração de novas idéias, a receptividade de idéias recentes, a causa das disputas e sua eventual resolução.

Paralelamente a essas idéias sobre o desenvolvimento do conhecimento científico do mundo, deve haver também alguns estudos de casos de disputa na aplicação do conheci- 


\section{ensaio}

vol $5 \cdot \mathrm{n}^{\circ} 2 \cdot$ out 2003

mento científico, com o principal objetivo de iluminar a gama de considerações (científicas e não científicas) envolvidas no alcance de qualquer decisão prática. Aqui também há ligações claras com a compreensão dos métodos científicos de investigação - em particular idéias sobre fidedignidade dos dados e a diferença entre dados e explicação. Os estudantes devem ter alguma idéia sobre estudos extensivos, pelo menos um ao longo de cada ano escolar, no qual trabalhem em grupo em questões práticas que requeiram deles, como grupo, tomar e defender decisões com conseqüencias práticas. Esse tipo de trabalho tem de ser sustentado por ampla quantidade de subsídios e dados.

\section{ALGUMAS CONCLUSÕES}

Na introdução desse artigo, sublinhei algumas áreas de preocupação sobre o currículo de ciências vigente: a evidência de que pouco é aprendido, a sensação de que o que é oferecido pode carecer de motivação e necessidade para os estudantes, a rígida uniformidade de seqüência. Como poderia um currículo para compreensão do público esboçar as preocupações citadas acima?

Primeiro, penso eu, proporcionando-se uma base melhor para melhoria da compreensão de idéias-chave e para avaliação da extensão da compreensão das mesmas. Isso pode ser feito pela identificação clara de alguns modelos-chave como um núcleo de conteúdo a ser pensado e pelo fornecimento de uma rede que possibilite clarear metas a serem postas para o desenvolvimento de uma compreensão dos métodos científicos e da ciência como um empreendimento social. Para muitos dos modelos-chave há um corpo considerável de dados de pesquisa sobre as idéias das crianças, dificuldades de aprendizagem e estratégias para tratá-las. Onde não houver, a clareza sobre os objetivos nos ajudaria a determinar prioridades para pesquisa posterior e desenvolvimento de abordagens.

Segundo, gostaria de sugerir que uma ênfase mais tecnológica junto com o foco em um pequeno número de modelos, poderia ter uma chance melhor, se apresentada de modo mais imaginativo, de captar e prender o interesse de mais estudantes, do que um currículo cuja estrutura e racional são frequentemente pouco claros para professores e devem mesmo parecer menos claros ainda para os alunos.

Terceiro, gostaria de sugerir estudos de casos do desenvolvimento histórico das idéias, do trabalho científico real (tanto contemporâneo quanto histórico), de disputas sobre aplicações da ciência, e investigações práticas mais extensas com foco em uma reunião de evidências persuasivas para sustentar uma conclusão. Isso também proporciona contextos apropriados para os estudantes exercerem suas opiniões e pontos de vista próprios e defendê-los, como também um meio de variar a seqüência de passos nas aulas de ciências - com grupos de aulas mais destinadas ao desenvolvimento intenso de idéias- 
chave seguidos de outros nos quais os alunos se envolvam em trabalhos que estimulem o uso de sua compreensão em desenvolvimento dessas idéias e assim as consolidem e reforcem.

O currículo de ciências como proposto acima não passa de um esboço reforçado. Não está trabalhado em detalhes. Aspectos de sequiência e tempo não foram considerados. Outros podem identificar ou requerer outras prioridades. Espero que esse artigo possa estimular o debate. Se quizermos mover-nos na direção de um currículo mais adequado à tarefa para o qual ele é requerido, a de um elemento central no currículo de todos os jovens, precisam ser postas questões difíceis e respostas convencionais precisam ser mudadas.

Primeiro, precisamos decidir por que queremos ensinar ciências para todos os jovens ; a partir disso talvez possamos trabalhar $o$ que queremos ensinr-lhes. Então a pesquisa, intimamente unida ao desenvolvimento e avaliação de abordagens e materiais didáticos, poderá, talvez, nos ajudar a descobrir como ensinar melhor essas idéias. Isso, penso eu, é o projeto no qual a comunidade de ensino de ciências precisa se engajar agora, como assunto de alguma urgência. Se esse artigo contribuir para abrir essa agenda, então terá servido a seu propósito.

\section{REFERÊNCIAS BIBLIOGRÁFICAS}

ANDERSSON, B. Pupils' conceptions of matter and its transformations age 12-16, Studies in Science Education, 18, 53-85, 1990.

CHAPMAN, B. The overselling of science education in the 1980's, SSR, 1991, 72(260), 47-63.

CLAXTON, G. Educating the Inquiring Mind: The Challenge for School Science. Harvester Wheatsheaf, 1991.

DES/WELSH OFFICE, Science in the National Curriculum. HMSO, 1991.

DRIVER, R.; SQUIRES, A., RUSHWORTH, P.; \& WOOD-ROBINSON, V. Making Sense of Secondary Science: Research into Shildren's Ideas, Routledge, 1994.

DURANT, J.; EVANS, G. \& THOMAS, G. The public understanding of science, Nature, 340, 11-14, 1989.

GAMBLE, R, DAVEY, A; GOTT, R \& WELLFORD, G. Science at age 15. Assessment of Performance Unit. Science Report for Teachers: 5, DES/WO/DENI, 1985.

JENKINS, S, Misappliance of science, The Times, 27 de Agosto, p. 14, 1994

LAYTON, D. Technology's Challenge to Science Education, Open University Press, 1993.

LAYTON, D.; JENKINS, E.; MACGILL, S. \& DAVEY, A. Inarticulate Science? Studies in Education Ltd, 1993.

MILLAR, R. what is the scientific method and can it be taught? IN; Wellington, J.J. (ed) Skills and Processes in Science Education: A Critical Analysis. Routledge, 1989.

MILLAR, R. \& DRIVER, R. Beyond processes, Studies in Science Education, 14, 33 62, 1987.

MILNER, B. Why teach science and why to all? In: NELLIST, J \& NICHOLL, B. (eds.), The ASE Science Teachers' Handbook, Hutchinson, p. 1-10, 1986.

SOLOMON, J. Teaching Science Technology and Society, Open University Press, 1993.

THOMAS, G. \& DURANT, J. Why should we promote the public understanding of science? Scientific Literacy Papers, 1, 1-14. University of Oxford Department of External Studies, 1987.

WOLPERT, L. The Unnatural Nature of Science, Faber, 1992. 